Received Date : 19-Apr-2016

Revised Date : 28-Oct-2016

Accepted Date : 19-Dec-2016

Article type : Original Article

\title{
Ultrasound as a technology of reassurance?: How pregnant women and health care professionals articulate ultrasound reassurance and its limitations
}

\author{
Gareth M. Thomas ${ }^{1}$, Julie Roberts ${ }^{2}$ and Frances E. Griffiths ${ }^{3}$ \\ ${ }^{1}$ School of Social Sciences, Cardiff University, Glamorgan Building, King Edward Avenue VII, Cardiff, CF10 \\ $3 W T, U K$ \\ 2 Division of Midwifery, School of Health Sciences, University of Nottingham, Tower Building, University \\ Park, Nottingham, NG7 2RD, UK \\ ${ }^{3}$ Warwick Medical School, University of Warwick, Coventry, CV4 7AL, UK
}

\begin{abstract}
The premise that ultrasound technologies provide reassurance for pregnant women is well-rehearsed. However, there has been little research about how this reassurance is articulated and understood by both expectant mothers and health care professionals. In this article, we draw on two qualitative UK studies to explore the salience of ultrasound reassurance to women's pregnancy experiences whilst highlighting issues around articulation and silence. Specifically, we capture how expectant parents This is the author manuscript accepted for publication and has undergone full peer review but has not been through the copyediting, typesetting, pagination and proofreading process, which may lead to differences between this version and the Version of Record. Please cite this article as doi: $10.1111 / 1467-9566.12554$
\end{abstract}

This article is protected by copyright. All rights reserved 
express a general need for reassurance and how visualisation and the conduct of professionals have a crucial role to play in accomplishing a sense of reassurance. We also explore how professionals have ambiguities about the relationship between ultrasound and reassurance, and how they subsequently articulate reassurance to expectant mothers. By bringing two studies together, we take a broad perspectival view of how gaps and silences within the discourse of ultrasound reassurance leave the claims made for ultrasound as a technology of reassurance unchallenged. Finally, we explore the implications this can have for women's experiences of pregnancy and health care professionals' practices.

\section{Keywords}

Patient-professional interaction; pregnancy; prenatal care; reassurance; risk; ultrasound

\section{Introduction}

Ultrasonography has become a key tool in the medical surveillance and management of pregnancy in the UK. Researchers have explored the social, cultural, and political implications of ultrasound and how the coupling of human and machine changes the relationship between expectant parents, particularly mothers, and the foetus (Mitchell 2001, 2004; Mitchell and Georges 1997; Roberts 2012a, 2012b; Roberts et al. 2015a, 2015b; Sandelowski 1994; Taylor 1998, 2008; Thomas 2015, 2017). Ultrasound has a number of clinical uses in prenatal care as well as 'psychological benefits' (Taylor 2008), with reassurance being widely recognised as one such benefit. The discourse of ultrasound reassurance is reproduced in pregnancy guides, professional discourse, and the accounts of expectant parents (Bashour et al. 2005; Gammeltoft and Nyugến 2007; Garcia et al. 2002; Taylor 1998). To some extent, this reflects a wider faith in the reassuring value of diagnostic and imaging tests (van Ravensteijn et al. 2012), but it also takes on particular nuances in the context of pregnancy which is frequently framed as stressful, risky (Roberts et al. 2015b; Thomas and Lupton 2016), and 'tentative' (Rothman 1994).

However, the premise that ultrasound is a technology of reassurance is rather problematic, with sociological and anthropological literature demonstrating how ultrasound scans can create more anxiety for women (Baillie et al. 2000), how surveillance exacerbates awareness of responsibilities and risks (Hammer and Burton-Jeangros 2013), how reassurance is limited (accuracy, time, genetic conditions screened for), and how scans disempower expectant mothers by disputing their embodied knowledge of pregnancy (Sandelowski 1994). 
In this article, we critically engage with the notion of ultrasound reassurance. By analysing data from two qualitative studies, we highlight issues around articulation and silence. Informed by Taylor's claim that ultrasound reassurance exists in relation to repressed fears (Taylor 2008: 62) together with a wider theoretical and empirical literature on the medicalisation of pregnancy (Oakley 1984), the reassuring value of medical surveillance via technologies (Parsons et al. 2000), risk discourse within pregnancy and parenthood (Lupton 2012), and the routinisation of ultrasound (Roberts 2012a Thomas 2017) - we take seriously pregnant women's desire for reassurance and their reports of feeling reassured while exploring what is missing from, and what is most difficult to articulate in, the discourse as produced in interviews and observations. In so doing, we contribute to broader debates in maternity care and health care more generally around the interplay between technology, fear, risk, un/certainty, and articulation. Ultrasound scans, in this respect, are not unique. By taking them as a case-in-point, we explore how the desire for reassurance during pregnancy is accompanied by downgrading women's embodied knowledge and promoting the use of risk-averse surveillance techniques in maternity care (Martin 1998), whilst leaving the value of the technology unquestioned.

\section{Background}

\section{Pregnancy, risk, and ultrasound}

Women's experiences of pregnancy are shaped by pervasive discourses that represent pregnancy as a 'risky' condition (Hammer and Burton-Jeangros 2013)'. Women are expected to participate in selfsurveillance during pregnancy, engaging with available services and technologies as well as conforming to certain norms of behaviour. The moral weight attached to compliance with medical advice is particularly great in pregnancy (Roberts et al. 2015b; Thomas 2017). Scholars have long seen routine use of ultrasound in maternity care as an exemplar of medicalisation (Oakley 1984). More recently, it is acknowledged that medicalisation is deeply internalised (Rothman 2014) and managing one's own health through actively engaging with medical technologies has become a moral imperative, especially for women who bear responsibility for their own health and their children's health (Clarke, Shim et al. 2003). Maternal moral responsibility for foetal wellbeing, and a cultural imperative to curtail anxiety for the sake of the foetus (Ogle et al. 2011), arguably limit women's capacity to resist this risk discourse. For Burton-Jeangros (2011), medicalisation and technocratic care promotes the idea that taking a perceived 'risk' challenges women's status as 'good' (future) mothers. This might include declining prenatal tests, ultrasound scans included. Pregnancy, therefore, involves a mediated morality of self-surveillance based on technocratic risk-averse norms.

Ultrasound has become a routine part of antenatal care in many parts of the world. In the UK, all women are offered two scans via the NHS, free at point of access. These are offered around 12 weeks for 'dating' and 20 weeks for anomaly detection and uptake is high: $89.8 \%$ for dating scans and 98.5\% for anomaly scans (Redshaw and Heikkila 2010). The guidance from the National Institute for 
Health and Care Excellence (NICE) is specific in the evidence-based reasons for using ultrasound routinely in pregnancy: to consistently date pregnancies to reduce the incidence of induction of labour for prolonged pregnancies, and identify anomalies so parents can make decisions about and to prepare for management of the pregnancy, birth, and child. However, it has been suggested (Taylor 1998) that routine ultrasound also provides women with psychological benefits including increased awareness of the foetus, improved compliance, and - our focus here - reassurance.

\section{Reassurance and ultrasound}

For Lippman (1991) and Taylor $(1998,2008)$, the claim that ultrasound offers women reassurance is complex and problematic. Working from different disciplinary perspectives, they claim any reassurance offered by ultrasound exists in tension with its function in prenatal testing. When reassurance is invoked as a 'psychological benefit', it is on the presumption that ultrasound will not reveal either foetal death or foetal abnormality. However, the justification for routinely offering ultrasound is an expectation that foetuses with abnormalities, clinically defined, will be identified and the pregnancy, in all likelihood, terminated (Taylor 1998: 21). According to Taylor (2008: 62), the reassurance ultrasound may provide 'exists only in relation to its repressed opposite of dread - of the loss of pregnancy, of foetal abnormality or death, or of agonising dilemmas of abortion'. If ultrasound offers women reassurance that their pregnancy is 'normal', it 'does so by granting tentative exemptions on a case-by-case basis from the broader conviction that pregnancy in general is inherently bound to go awry' (Taylor 1998: 21). That is, it is premised on the construction of risk and assumptions about the value of certain information (Lippman 1991: 23). The exemptions granted are tentative since not all conditions or abnormalities are detected and it only offers a time-limited snapshot of the pregnancy, with no guarantee that health issues will not emerge later (Lippman 1991, Taylor 2008).

Research on women's experiences support the claim that ultrasound has reassuring qualities. Studies in a range of national contexts found that ultrasound examinations are desired, much anticipated, and can offer reassurance about the health of the pregnancy and foetus (Georges 1996, Bricker, Garcia et al. 2000, Garcia, Bricker et al. 2002, Bashour, Hafez et al. 2005, Gammeltoft and Nguyến 2007). However, studies also highlight that scans are not always reassuring and reassurance is not always long-lasting. For instance, an impending examination raises the possibility that an issue will be detected and, thus, raises anxiety (Reid, Sinclair et al. 2009). Women in Harpel's (2008: 302) research expressed little anxiety in their pregnancy until shortly before a scan when it crossed their minds that there could be something 'wrong' with their baby, reporting 'sleepless nights, dreams about the foetus' health, short tempers and difficulties concentrating before the exam'. Hammer and Burton-Jeangros (2013) take a wider sociocultural view to argue it is the routinisation of screening in pregnancy that fosters anxiety by increasing awareness of the risks of conditions and diseases. Interestingly, several authors report that some mothers express apprehension even after 'negative' 
results, with two-thirds of women in Baillie et al.'s (2000) research describing residual feelings of anxiety after a 'normal' scan result.

Research also shows that the clinical objectives of ultrasound scans are not understood by all women and that a 'high risk' result can be unexpected (Baillie, Smith et al. 2000), inevitably increasing their anxiety (Whynes 2002). Routine and commercial scans too create the potential for concerns to be raised that require further investigation (Roberts et al. 2015b). On this point, Burton-Jeangros et al. (2013) claim that during ultrasound, health care professionals and expectant parents are not only confronted with the need to comprehend complex probabilistic information, but are also reminded of how much uncertainty results from such data. This probabilistic information may not always be reassuring since it is not easily understood, nor does it offer women the certainty they seek (Reid, Sinclair et al. 2009, Hammer and Burton-Jeangros 2013). For Burton-Jeangros et al. (2013: 145), this is emblematic of manufactured uncertainty (using Giddens' term) whereby risk management strategies 'open up possible scenarios that individuals have to anticipate, without providing the complete information necessary to make informed decisions'. In some instances, this leads women to defer thinking about what they will do with this risk information until the specific test is complete (Aune and Moller 2012).

In addition, as risk information is based on population health, whereas patients seek information about their individual risks and outcomes, health care professionals and service users may think about risk in different ways (Burton-Jeangros et al. 2013). Aune and Moller (2012: 15) describe ultrasounds, as tools of risk assessment, as shifting women from a position of 'complete uncertainty to quantified uncertainty', with probabilistic information being shaped by sociocultural factors such as family history, obstetric history, and cultural and religious values. There is little research on health care professionals' perspectives of ultrasound, though Edvardsson et al.'s (2015) study captures how Australian midwives believe ultrasound has advantages but also contributes to the increased medicalisation of pregnancy, uncertain decision-making, and parental anxiety.

The analysis presented here extends this field of study by exploring how pregnant women express their need for reassurance and the role of ultrasound within that. It also addresses a gap in the literature by capturing professionals' views of the reassurance value of pregnancy ultrasound and how they, as care providers, articulate reassurance in their clinical practice. Finally, what is said or is silenced when articulating reassurance has not been a key focus for research on ultrasound or many other prenatal technologies. By addressing such concerns here, we suggest that the silences within the discourse of ultrasound reassurance matter because they make the discourse harder to challenge, and may also make it harder for women to receive the care they need.

\section{Research contexts: two studies}

Study one was undertaken by Roberts and Griffiths and took place over eleven months in 2012-13 to explore pregnant women's experiences of commercial ultrasound. Women were recruited from two 
sites operated by one company in different large UK cities. They were interviewed briefly before their scan appointment and in more depth at home a few days following their appointment. Forty-eight women participated in pre-scan interviews and twenty-one completed a follow-up interview. Analysis involved inductive thematic analysis guided by the research questions and knowledge of the literature. Roberts and Griffiths collaborated on the analysis and a subset of transcripts were reviewed by a service-user representative and themes were discussed, with reassurance emerging as a strong theme in the data. This theme was also reported briefly among four others in an early article (reference removed). Here, we interrogate this finding further. Data coded to the theme of reassurance was re-read and further themes were identified. Whilst initially frustrated with women's seemingly vague and underdeveloped narratives of 'checking everything's ok', Roberts and Griffiths became increasingly fascinated by issues of discourse and articulation.

Study two - an ethnography of prenatal screening for Down's syndrome in two UK clinics was conducted by Thomas for around one year beginning in 2011. Together with interviewing sixteen health care professionals and analysing policy/hospital documents, Thomas spent over two-hundred hours observing the everyday practices and interactions of health care professionals. Thomas' research on ultrasound scans included observing Down's syndrome screening (nuchal translucency scans), early pregnancy scans, wellbeing scans, cardiac scans, anomaly scans, ' $4 \mathrm{D}^{\prime}$ scans, and diagnostic tests (i.e. amniocentesis/CVS). The majority of ultrasound scans observed were those in which Down's syndrome screening was offered. This involves a scan where a nuchal translucency (skin at back of a foetal neck) and foetal size is measured. These figures are combined with other factors (e.g. maternal age, weight) and within a period of two weeks, parents receive a 'risk factor', a numerical variable establishing the chance of a foetus having Down's, Patau, and Edward's syndrome. Data reported in this article includes observations at two clinics and interviews with health care professionals $(\mathrm{N}=16)$. Data was analysed by grouping material together to establish connections and contradictions in observations and the accounts of participants. Data was read alongside literature, allowing for an inductive and processual approach, until intricacies and relationships were identified. This allowed Thomas to crosscheck data to capture patterns and identify deviations to upset original interpretations or offer further explanations. Ethical approval was granted by NHS and university research ethics committees for both studies. For more information on methodology and data analysis for both studies, see (Roberts et al. 2015a, 2015b; Thomas 2017).

The studies were brought together after Thomas and Roberts met at a conference and discussed their research. It was clear that the theme of ultrasound reassurance had emerged in both studies and that they drew on similar literatures and methodological approaches. Crucially, both studies emphasise attending to the personal experiences and interactions of participants as well as the politics of reproduction. After exchanging ideas, we each revisited the data coded to the theme of reassurance. We shared anonymised data and performed a supplementary analysis (Heaton 2004) in 
order to further develop themes already identified in the original analysis. This allowed us to undertake an adapted 'pooled case comparison' (West and Oldfather 1995) to learn from the juxtaposition of two distinct but complementary datasets while remaining alert to their specificities. This was a gradual and co-constructed process that lasted for a number of months and resulting in the analysis presented here.

Our analysis adds value to each study by drawing on the perceptions of health care professionals and service-users to include the voices of both groups and to explore the potential to illuminate events at the interface between the two, including commonalities and disparities. That said, there are limits to our approach. Each study was carried out in different sites, at different times, and in different contexts. The women in both studies may not represent a general population in terms of their accessing of services or their need for reassurance. Yet comparing themes of reassurance, articulation, and silence across the datasets suggests that they may have relevance in a wide range of maternity and health care contexts. We posit, therefore, that our combined findings illustrate interesting elements of both the discourse and practice of foetal ultrasound and raise questions about its role as a technology of reassurance.

\section{Study 1: Reassurance and expectant mothers}

\section{'You just want to have the scan and make sure everything's ok'}

In study one, reassurance was an issue for women at all stages of pregnancy; participants between eight to thirty-seven weeks pregnant talked about reassurance. However, there were clear differences between women in the first trimester and those in later pregnancy. Women in early pregnancy were more likely to name their fears and express worries in biomedical terms:

I just want to know that the pregnancy is viable so it's not something like a missed miscarriage or something like that.

Well is it in the right place, so it's not ectopic or something like that.

Most women in the early stages of pregnancy sought reassurance they were pregnant and the pregnancy was viable and healthy. This could be linked to a lack of other signs and symptoms of pregnancy, but equally with physical sensations like discomfort. Women contrasted their embodied knowledge with ultrasound, implying that the former was not to be trusted. Some women 'felt' pregnant but feared they may no longer be; others did not feel pregnant, although tests suggested they were:

It was literally to see that it was viable and that I wasn't just still feeling like I was pregnant and wasn't. 
This reflects Mitchell's (2001) observations that women often give little credence to bodily changes and rely on technology to confirm pregnancy. It also reflects the 'tentative' (Rothman 1994) nature of early pregnancy in which women are often encouraged to maintain some emotional distance and delay attachment until a period of high-risk passed - usually 12 weeks when the risk of pregnancy loss drops sharply (Ross 2015). It may be that this distance enables, or even requires, the naming of women's fears in biomedical terms in a way that is not observed in later pregnancy.

It was striking from early analysis that most women in the second or third trimester expressed their desire for reassurance in very general terms, wanting to know that 'everything' was 'okay':

I just wanted to check, make sure things are okay with the baby and everything's going alright. Just routinely really.

That little bit of peace of mind again isn't it? Because I want to see what's going on in there...make sure that she's all okay and she's got everything she's supposed to.

In a small number of cases, the scan was booked by a concerned partner or family member seeking reassurance for a pregnant woman. Where women were slightly more specific, they used synecdoche and humour to express their worries about foetal health:

I wanted to...not from a horrible point of view but I just wanted to check that it was alright...it didn't have three eyes or something and my nose [laughs]...just you know five fingers, five toes all that type of stuff.

Here, (five) fingers and (five) toes stand in for a foetus that is, at once, baby-like and not potentially monstrous (three eyes). Interestingly, women in the second and third trimester did not articulate their concerns in clinical terms that could be easily matched, or not, with the aims or capabilities of ultrasound scans. For most, there was no clear prompt for their worries, although some indicated factors in their social environment which influenced their thoughts. For instance, one participant was a doctor who felt her profession made her more aware of what could go wrong, one had unspecified health issues in the family, and one recognised the internet as a source of anxieties ('I've got it into my head that something is going to go wrong...so I've stopped reading now because I'm not sleeping'). Others located the need for reassurance in their own personality:

I think it's just because it's my first... and I'm a bit...of a control freak and it's the one thing I can't control and I can't see what's going off and its driving me mad. 
These very general expressions of worry are difficult to interpret. In one sense, perhaps they reflect the routinisation of medicalised prenatal care and how foetal ultrasound has become a 'normalised and unquestioned examination' (Edvardsson et al. 2015). However, all participants had, or intended to have, routine ultrasound scans, so the seeking of additional scans suggests the need for further interpretation. General expressions of anxiety also seem to reflect the construction of pregnancy as a risky condition (Rothman 2014), where risks are multiple, diffuse, and often poorly specified. This discourse creates a heightened sense of risk with little concrete information about type or magnitude of risk, whilst making women responsible for self-surveillance in pursuing a positive pregnancy outcome. Generalised articulations of risk and reassurance also reflect Taylor's (2008) claim that the reassurance ultrasound can offer exists only with respect to its repressed opposite: fear of loss, foetal abnormality, or abortion. The repression of this aspect of ultrasound is reflected here in interview accounts. Our participants are, understandably, reluctant to name fears and there may also be, arguably, an assumption of normality in which detailed thinking about any prenatal diagnosis or health issue is delayed until after the scan.

In the context of generalised risks and fears, we may deliberate about just how clear women are about what ultrasound can, and cannot, assess. There are long running concerns about informed consent for ultrasound, usually framed in the literature in terms of women's limited knowledge about its clinical aims (Ockleford et al. 2003). It was outside the remit of either study to assess women's understanding of ultrasound, but our analysis raises questions about how we understand their engagement with it, particularly as fears of loss and fears of foetal abnormality are repressed in the discourse of ultrasound reassurance. This norm of unarticulated anxieties could present problems for professionals and we can wonder how they can reassure expectant parents unless they know what concerns them.

\section{Seeing for yourself and hearing 'everything is ok'}

Women in our study all reported that they found ultrasound scans reassuring, namely as they allowed women to see the foetus themselves:

It's very reassuring having the scan and seeing that everything is okay.

For some, this visualisation was central to reassurance, a finding reflected by Øyen and Aune's (2016) study with pregnant Norweigen women, and could not be provided by other professionals or services:

I think if you get something into your mind, until you see that it's...she [community midwife] was telling me that the baby's okay, there's nothing to worry about...But I think that until you see that it's okay, you're never going to be sure. 
It is interesting to contrast this with the following quote in which the participant claims that being told the baby is okay is 'all you need', but this is also dependent on 'seeing' the foetus:

Just hearing those words, everything is okay, that's all you need...that's all you need to hear sometimes.

And then it's just a shame because the NHS doesn't have time to do that for you.

What the NHS does not have time to do, the participant explains, is offer scans to women when women feel they need them. This participant was not alone in feeling frustrated that she had to use a commercial service for a scan that she perceived to be necessary. However, her articulation of need has no resonance with clinical guidelines regulating the use of ultrasound in pregnancy. It was a common complaint that gaps between routine scans were too long. Such comments identify the timelimited nature of ultrasound reassurance; scans offer reassurance for now, a temporary snapshot of foetal wellbeing.

How sonographers performed the scan and articulated information was also crucial for women to reassure them. Study 2 offers more information about this, but the women in study 1 provide some insight into what they found reassuring:

[The sonographer's] so informative... and he just reassures you the whole way through.

\footnotetext{
She sort of pointed out what everything was and she said 'there's the heartbeat that you can see there'. So it was just like every sort of question that you're kind of worried about in your mind, she pre-empted and answered it for me really.
}

Reassurance is associated with taking time, giving information, and showing women around the screen. The sonographer in the second quotation is credited with soothing even those worries that the woman did not express. In contrast, NHS scans sometimes felt 'rushed' or sonographers were felt to not have spent enough time on the examination. There were very few complaints about the commercial scans in this respect, but one woman talked of her disappointment:

He didn't talk much...you kind of want the reassurance...I know it's not an anomaly scan but...you just want him to say that there's nothing obvious you know? I asked him about that and he said no, I can't comment on that, this is just a growth scan.

Our impression is that the sonographer declined to offer general reassurance - that everything is okay and adhered to the aims of the scan as advertised: assessing foetal growth. Just as women often accept routine NHS scans for reasons that do not match perfectly with the NHS's aims, so too do women book particular kinds of commercial scans (e.g. growth scans, bonding scans, dating scans) for 
reasons that do not perfectly align with the advertised purpose. A strict adherence to the stated aims of the ultrasound scan, then, may fail to reassure parents.

\section{Study 2: Reassurance and health care professionals}

\section{'It's all for reassurance really but we can't always offer that reassurance'}

In this section, we present the views of professionals and, in turn, describe a disconnect between their criticisms of ultrasound and Thomas' observations of ultrasound in practice. Professionals in study 2 exhibit an awareness that women seek ultrasound for reassurance that a pregnancy is progressing as expected. They also recognise that when women receive inadequate care at a hospital, ultrasound scans at another clinic helps rectify this situation; 'all patients want is attention, doctors and midwives taking time to see them and not rushing the consultation, and reassurance' (midwife). This is particularly true if mothers had complications in earlier pregnancies and concerns about maternal age. This is common with regards to Down's syndrome screening; an increased maternal age is the only factor linked to a higher chance of having a baby with the condition (NHS Choices 2016).

However, for professionals, the vague expression of reassurance - as articulated by parents in study 1 - is problematic. One midwife, for example, worries that women have ultrasound for reassurance but do so 'without actually thinking it through'. When asked about Down's syndrome screening, another midwife claims that most women have this ultrasound scan as it offers 'reassurance that everything is alright' yet this should 'not be the reason to have it' and most mothers 'don't think of the consequences':

It's a lot of stress. It's that can of worms isn't it really? [The parents are] not thinking about the implications. They have the test, the 20 week scan. It's all for reassurance really but we can't always offer that reassurance.

For this midwife and others, using ultrasound for reassurance omits the idea that prenatal technologies may present expectant mothers with unexpected results, thus leading to difficult decisions about further medical interventions including diagnostic tests ('a can of worms'). When any test is used for screening purposes, 'the great majority of results are expected to be normal' (Daly 1989: 100) and mothers, as professionals suggest here, may be uninformed as to ultrasound's purpose (Whynes 2002). One midwife sonographer, for instance, claims that '[parents] just like to see the baby again, the heartbeat going, the baby moving, and some pictures but...they don't realise that it's not $100 \%$ [accurate]'. A sonographer suggests that this undercuts the governing principle of informed choice:

I don't think women fully understand the implications of screening. I don't think informed consent is truly ever achieved. And people will only get onto the couch without any real understanding of the 
ramifications if an enlarged nuchal translucency is found and that stands for any screening we undertake...Very few women are truly informed and give you informed consent.

There is an awareness among professionals of the limitations of medical and patient knowledge and their own communication. Relating to ultrasound, professionals express a concern that whilst mothers commonly undertake these in the pursuit of reassurance - as well as to obtain 'baby's first picture' (Mitchell 2001) and to try to determine foetal sex - such scans may produce results which create ethical dilemmas (i.e. whether to have diagnostic testing and/or a termination of pregnancy). They also share a concern that mothers do not fully appreciate that reassurance is temporal and may have 'ramifications' that are not initially considered. This assertion ties into their wider criticism among many professionals that mothers consent to procedures owing to their routinisation and their alleged reassuring qualities.

In study 2, expectant mothers appeared anxious about pregnancy, but this worry was frequently ambiguous; they were anxious about any abnormality more generally rather than specific genetic outcomes relating to the foetus. Nonetheless, we found that professionals interpret a lack of articulation around reassurance among expectant parents as a lack of knowledge - though this charge was not openly reported or implied during an ultrasound scan. This may sometimes be the case, but it may also be that parents have their own reasons for accessing ultrasound and these do not marry with the clinical uses set in policy and practice. For instance, the repressed 'dread' of loss, foetal abnormality, or abortion may initiate reluctance from parents to fully articulate their fears. Nonetheless, mothers seem to accept the medicalised and externalised concept of the body that requires careful surveillance and monitoring. Women, therefore, arguably undertake the ultrasound as routine (Hammer and Burton-Jeangros 2013) and to calm concerns in the absence or dismissal of embodied knowledge.

\section{Articulating reassurance: the ultrasound encounter}

In the ultrasound scans observed, professionals rarely articulate their concerns of ultrasound to parents. We do not speculate as to why this discrepancy occurs but, rather, we focus on what occurs in the clinic and how reassurance is articulated during ultrasound. In study 1, parents report that a professionals' conduct is important for reassurance. This extract from study 2 details a Down's syndrome screening consultation between a sonographer (S) and expectant mother $\mathrm{M}$ ):

S: Straight away you can see the head, the bum sticking in the air [MF laughs]. That's the heart beating there [points], the arm...the legs.

M: Having a rest bless him, or her! Do they sleep then?

S: They do. Do you see the arms by the side of the head?

M: Yeah.

S: Sorry for prodding you so much! If I get on your nerves, let me know! 
M: Don't worry about it [laughs]! Oh the little face! So are they not co-operating?

S: Not really. Just move that way a bit please, baby! There's the heartbeat anyway. It's lovely and strong. There's the little nose...I'll see if I can roll you back this way [MF] to try and annoy baby [MF laughs].

M: Yeah see if you can wind them up!

S: I can see the NT now. Do you see this line here, and another line [points]? And this black line in the middle? That's the nuchal translucency. We like it to be under $3.5 \mathrm{~mm}$ and I can see just from that that it definitely is. It's tiny.

M: So it doesn't look as if it's a problem?

S: No. It's very small that is. It looks about $2 \mathrm{~mm}$ and we like it under $3.5 \mathrm{~mm}$.

M: Ah great. I'm 40 now so I was, you know.

$\mathrm{S}$ : Yes. It is a known risk factor for Down's syndrome.

The sonographer comments on the 'bum sticking in the air', tells the mother to notify her if she 'get[s] on your nerves', and urges the baby to move ('just move that way a bit please, baby!'). These are the 'social' dimensions of ultrasound, defined as elements outside what can be loosely described as clinical information (Mitchell 2001; Taylor 2008). This includes sonographers describing a 'baby' (not 'foetus') as 'he' or 'she', 'cute' or 'beautiful' or 'normal' or 'gorgeous', and ascribing movement to being 'playful' and 'lively' (a lot of movement) or being 'lazy' or 'sleeping' (little movement). In addition, they frequently identify a baby's features connected with family attributes (e.g. 'the baby has got your nose!'). Professionals create a playful atmosphere once convinced that no prospective foetal problems are evident. They also offer reassuring utterances to mollify anxious parents and pull in partners and others, with humour playing a key role in this.

We argue that these social dimensions of ultrasound have a reassuring quality. By sticking to the script of a happy routine scan as a social event (Taylor 1998, 2008), professionals reassure parents that the pregnancy is progressing well. The importance of talking is clear here too. If a professional is not talking (as participants indicate in study 1), this may not reassure parents. This was evident in one scan where a couple was notified that their child would likely be diagnosed with cystic hygroma. In this scan, the social dimensions of ultrasound were absent. In their study, Larsson et al. (2010: 4) identified the 'frightening silence' felt by some parents' experiences of their ultrasound scan, with no words being spoken denoting a 'sense of seriousness' and intensifying the anxiety felt at the start of the consultation. The social dimensions of ultrasound, then, are vital for offering reassurance, as are the more 'clinical' dimensions of ultrasound. These can include a sonographer showing foetal movement and a heartbeat, the monitoring of placental blood flow and amniotic fluid, and measuring an NT when screening for trisomies (Down's, Edward's, Patau).

Returning to the extract above, the sonographer cites the nuchal translucency (NT) and indicates that its current size is 'tiny'. Reassurance is assured with the statement that it seems small as an enlarged NT is linked to a possible diagnosis of foetal abnormality. The mother accounts for her decision to have the scan by citing her maternal age and the sonographer later repeats 'it's all looking 
fine' and the NT is 'small which is good'. This reassurance also connects with ideas of professional status and skill. In one NT scan, a sonographer reassures parents by claiming that 'it's one of the clearest scans I've ever seen' and asserts that the NT is of a 'normal' size. The use of terms like 'normal', 'lovely', 'good', and 'healthy' with respect to the foetus and the pregnant body offer reassurance to parents that the pregnancy is progressing as expected. However, we may question whether this also creates problems. For instance, there is no explanation of what an NT measurement entails. Although the sonographer says age is a 'known risk factor for Down's syndrome', there is no description of what a small or large NT $(>3.5 \mathrm{~mm})$ means. This assumes a knowledge and avoids naming the specific 'problem' being sought out, meaning that this information becomes silenced.

Nonetheless, the reassuring quality of the medical side of ultrasound is also apparent during a $4 \mathrm{D}$ scan with a male and female expecting twins (one diagnosed with cleft lip) and a sonographer who claims the scan is being done to 'erase some of [your] fears'. The sonographer provides reassurance by praising a doctor who provided an earlier diagnosis ('[Doctor's] one of the best in the business for this'), acknowledges the other 'normal' foetal features ('baby is on the 50th percentile...which means it's right in line with the average'), flatters the female by saying 'whatever you're doing, you're doing it right' (possibly absolving her of any self-blame), and points out foetal features ('here's the nose, the head, the forehead, the eyes, the nostril, the upper lip and the little cleft there'). The sonographer says the cleft is 'very small', 'tiny', and 'completely treatable', reiterating her expertise by claiming 'I've been scanning before Gareth was born and I can say that this is not a huge, massive cleft at all'. Despite the serious subject matter, the sonographer also reassures the parents by using light-hearted retorts and playful descriptions: she identifies the two foetuses as being 'right on top of each other' ('you've got one in the basement and one in the penthouse!'); she amuses the female by shaking her stomach using a transducer; she urges the foetus with a cleft lip to 'co-operate' and stop giving her 'grief' so 'pictures' are possible, and; she playfully scorns the foetus for allegedly raising a middle finger (known in the UK as an obscene gesture) and having 'his legs, arms, hands, everything up there in front of the face'. As with other scans, reassurance is accomplished here through both the medical and the social dimensions of ultrasound.

\section{Discussion}

In this article, we explored how expectant mothers express a desire for reassurance through ultrasound often in general terms that do not directly reference their own fears and anxieties. We also recognised the relative role of both visual and verbal articulation in achieving reassurance. In what followed, we captured how professionals express ambivalence about the reassuring qualities of ultrasound in research interviews. However, such concerns are regularly made absent during scans, with professionals offering reassurance in explicit ('clinical') and implicit ('social') ways. Although ultrasound is viewed as a technology of reassurance in many respects, we have identified what this means for the different people involved and how, in turn, much remains unarticulated by 
professionals and parents. Whilst the concerns of professionals around the alleged reassuring qualities of ultrasound are silenced, so too are parents' own specific claims about what they seek reassurance for, or what would best address their concerns.

Parents' lack of articulation and specificity about the purpose of ultrasound might be interpreted as a sign of a lack of understanding about the technology; informed consent for ultrasound examination has been an ongoing concern in the literature (Ockleford, Berryman et al. 2003, Smith, Titmarsh et al. 2004). However, these two datasets suggest that the problem of articulating its purpose, including the benefits and limitations of ultrasound, may reside partly in wider discourses about the technology. If ultrasound reassurance exists 'only in relation to its repressed opposite of dread - of the loss of pregnancy, of foetal abnormality or death, or of agonising dilemmas of abortion' (Taylor 2008: 62), it is perhaps the cultural norms of keeping one's fears for foetal wellbeing unspoken at work here. Indeed, it may be that this vague articulation results from the routinisation of pregnancy ultrasound that figures pregnant bodies as 'at-risk' (Thomas and Lupton 2016) and the subtle repression of fears and anxieties among parents. However, we also reflected that when participants used humour, synecdoche, and metaphor to refer to fears, we (as researchers) mirrored this, mindful of social rules around risk and surveillance in pregnancy; it felt difficult, insensitive, and perhaps unethical to urge women to name their pregnancy-based fears, and we colluded with their reluctance to name the possibility of prenatal diagnosis, foetal death, and so on.

In Thomas' study, health care professionals demonstrated a willingness to talk about risk and prenatal diagnosis with a researcher yet observations of their professional discourse, in interactions with expectant mothers, suggest they too rely on oblique and incomplete references to risk unless, and until, the interaction requires a more 'direct' approach (i.e. once a diagnosis is suspected or established). A remarkable feature of ultrasound is that a diagnosis, or risk of diagnosis, emerges during the scan; the sonographer is looking, interpreting, and deciding what to say to those present. Professionals obliquely hint at possibilities, setting the scene for what may need to be said if expectations of 'normality' are not fulfilled. Professionals, then, stay with uncertainty until there is some level of certainty. As such, there is the potential for confusion and unmet needs, as well as mismatches between women's and health care professionals' perspectives. If parents do not express their fears, professionals may not be in a position to respond to their needs. There is some evidence in the literature that although the visualisation of the foetus is highly valued, women invest considerable effort in making connections between the image on the screen and their embodied experience (Roberts 2012b; Ross 2015). Thus, there is a concern that pregnant women do not articulate fears, which makes it tough to explore whether there are other ways that women may be reassured in pregnancy.

Simultaneously, if professionals do not express their fears (e.g. of detecting a condition, of expectant parents not understanding the scan's purpose), there is a risk of further routinising a complex procedure. By not conveying their own discomfort or ambiguities to expectant mothers, and 
by aligning with the principles of 'informed consent' and 'non-directive care' (i.e. their role is to provide clinical information about the foetus), there is a danger that they contribute to the normalisation of screening technologies. In short, silencing their concerns and anxieties means that the value of ultrasound (and prenatal screening more widely) is not articulated or debated, possibly creating circumstances in which ultrasound constitutes another 'expected' pregnancy procedure.

Gaps and silences in the discourse of ultrasound reassurance leave the claims made for the technology unchallenged. Ultrasound is restricted as a technology of reassurance since it can only offer reassurance for now and is limited to known conditions that can be visualised. Its routinisation may be partly responsible for women's need for reassurance in a social context where pregnancy is viewed as a risky condition (Hammer and Burton-Jeangros 2013; Lupton 2012). Acknowledging the limitations of the technology, and engaging in dialogue about what ultrasound can and cannot offer women (and what alternative/supplementary care may be beneficial), is perhaps a way to ensure women have critical access to ultrasound - which entails not only material and functional access, but the ability to understand the benefits and flaws of a technology and choose whether to engage with it. This would also promote the valuing of women's embodied knowledge during pregnancy, such as foetal movements, which can be vital to assessing 'risk', discouraging an over-reliance on visualising technology.

Moreover, our article - taking ultrasound scans as a paradigm case - has explored the interplay between prenatal technology, fear, trust, risk, un/certainty, and embodiment. Ultrasound supposedly reassures and offers comfort for women, yet it simultaneously emboldens a climate of risk-aversion and surveillance that can undermine them and intensify their dependency on medical intervention. This is undoubtedly fuelled by the interplay between risk, reassurance, and 'knowing', whereby some notion of certainty is sought as a desirable and achievable aim in a fundamentally uncertain state. However, as we recognised, the pursuit of certainty in pregnancy through prenatal techniques is often a momentary and futile aspiration. The lack of articulation from health care professionals about the limits of the technology leaves the discourse of ultrasound reassurance unchallenged and potentially leaves women to pursue an impossible level of certainty about their pregnancy outcomes. We urge others to assess our claims in different contexts; we suspect that many of our claims are not limited to maternity care but, rather, emerge in other forms of health care too.

Bringing two studies together at the analysis stage has limitations. Although we have found this to be a productive endeavour, both studies were conducted in different sites and further research might consider investigating ultrasound scan consultations from dual perspectives. Nonetheless, our studies stress the importance of examining the so-called reassuring qualities of prenatal tools and, so, we urge other scholars to examine the impact of 'reassuring technologies' on both service users and health care professionals in maternity care and in health care more generally. 


\section{Footnotes}

1. For further work on the relationship between risk, pregnancy, and childbirth, see a special issue in the journal Health, Risk \& Society (2014, volume 14, issue 1).

\section{Acknowledgements}

JR and FG would like to offer sincere thanks to the parents who participated in the research interviews as well as to Jan Steward and Ultrasound Direct for granting access to the research sites. We also thank Alice Verran who conducted some of the interviews and Catherine Ayre who provided expertise as a public involvement representative. GT would like to thank the healthcare professionals and expectant parents who participated in his study, together with the Economic and Social Research Council (ESRC) for funding it (grant number: ES/I019251/1). We all extend our thanks to the anonymous reviewers for helpful feedback on earlier drafts of the paper.

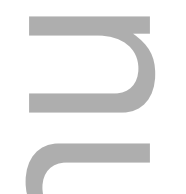

Address for correspondence: Gareth Thomas, Room 2.35, Glamorgan Building, King Edward VII Avenue,

Cardiff, CF10 3WT.

Email: thomasg23@cf.ac.uk

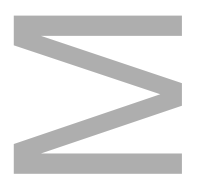

\section{References}

Aune, I. and Moller, A. (2012) 'I want a choice, but I don't want to decide' - a qualitative study of pregnant women's experiences regarding early ultrasound risk assessment for chromosomal anomalies, Midwifery, 28, 1, 14-23.

Baillie, C., Smith, J., Hewison, J. and Mason, G. (2000) Ultrasound screening for chromosomal abnormality: women's reactions to false positive results, British Journal of Health Psychology, 5, 4, 37794.

Bashour, H., Hafez, R. and Abdulsalam, A. (2005) Syrian women's perceptions and experiences of ultrasound screening in pregnancy: implications for antenatal policy, Reproductive Health Matters, 13, $25,147-54$. 
Bricker, L., Garcia, J., Henderson, J., Mugford, M., Neilson, J., Roberts, T. and Martin, M.A. (2000) Ultrasound screening in pregnancy: a systematic review of the clinical effectiveness, cost effectiveness and women's views, Health Technology Assessment, 4, 16, 1-193.

Burton-Jeangros, C. (2011) Surveillance of risks in everyday life: the agency of pregnant women and its limitations, Social Theory \& Health, 9, 4, 419-36.

Burton-Jeangros, C., Cavalli, S., Gouilhers, S. and Hammer, R. (2013) Between tolerable uncertainty and unacceptable risks: how health professionals and pregnant women think about the probabilities generated by prenatal screening, Health, Risk \& Society, 15, 2, 144-61.

Clarke, A. et al. (2003) Biomedicalization: technoscientific transformations of health, illness, and U.S. biomedicine, American Sociological Review, 68, 2, 161-94.

Daly, J. (1989) Innocent murmurs: echocardiography and the diagnosis of cardiac normality, Sociology of Health and Illness, 11, 2, 99-116.

Edvardsson, K., Mogren, I., Lalos, A., Persson, M. and Small, R. (2015) A routine tool with farreaching influence: Australian midwives' views on the use of ultrasound during pregnancy, $B M C$ Pregnancy and Childbirth, 15, 195.

Gammeltoft, T.M. and Nyugến, H.T.T. (2007) The commodification of obstetric ultrasound scanning in Hanoi, Vietnam, Reproductive Health Matters, 15, 29, 163-71.

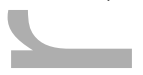

Garcia, J., Bricker, L., Henderson, J., Martin, M.A., Mugford, M., Nielson, J. and Roberts, T. (2002) Women's views of pregnancy ultrasound: a systematic review, Birth, 29, 4, 225-50.

Georges, E. (1996) Fetal ultrasound imaging and the production of authoritative knowledge in Greece, Medical Anthropology Quarterly, 10, 2, 157-75.

Hammer, R.P. and Burton-Jeangros, C. (2013) Tensions around risks in pregnancy: a typology of women's experiences of surveillance medicine, Social Science and Medicine, 93, 55-63.

Harpel, T.S. (2008) Fear of the unknown: ultrasound and anxiety about fetal health, Health, 12, 3, 295312. 
Harris, J.M., Franck, L., Green, B., Wilson, S. and Michie, S. (2015) The relationship between frequency of obstetric ultrasound scans and birthplace preference: a case control study, Midwifery, 31, 1, 31-36.

Heaton, J. (2004) Reworking Qualitative Data. London: Sage.

Larsson, A.K., Crang-Svalenius, E., Lundqvist, A. and Dykes, A.K. (2010) Parents' experiences of an abnormal ultrasound examination - vacillating between emotional confusion and sense of reality, Reproductive Health 7, 10, 1-10.

Lippman, A. (1991) Prenatal genetic testing and screening: constructing needs and reinforcing inequities, American Journal of Law and Medicine, 17, 1\&2, 15-50.

Lupton, D. (2012) 'Precious cargo': foetal subjects, risk and reproductive citizenship, Critical Public Health, 22, 3, 329-40.

Martin, E. (1998) The fetus as intruder: mother's bodies and medical metaphors. In Davis-Floyd, R.E. and Dumit, J. (eds.) Cyborg Babies: From Techo-Sex to Techno-Tots. New York: Routledge, 125-42.

Mitchell, L.M. (2001) Baby's First Picture: Ultrasound and the Politics of Fetal Subjects. Toronto: University of Toronto Press.

Mitchell, L.M. (2004) Women's experiences of unexpected ultrasound findings, Journal of Midwifery and Women's Health, 49, 3, 228-34.

Mitchell, L.M. and Georges, E. (1997) Cross-cultural cyborgs: Greek and Canadian women's discourses on fetal ultrasound, Feminist Studies, 23, 2, 373-401.

NHS Choices. (2016) Down's syndrome - causes. NHS Choices [Online]. Available at: http://www.nhs.uk/Conditions/Downs-syndrome/Pages/Causes.aspx [Accessed: 02 August 2016].

NICE (2010) Clinical Guideline 62 Antenatal Care. London: National Institute for Health and Care Excellence.

Oakley, A. (1984) The Captured Womb: A History of the Medical Care of Pregnant Women. Oxford: Blackwell. 
Ockleford, E., Berryman, J. and Hsu, R. (2003) Do women understand ultrasound prenatal screening for foetal abnormality?, British Journal of Midwifery, 11, 7, 445-9.

Ogle, J. P., Tyner, K.E. and Schofield-Tomschin, S. (2011) Watching over baby: expectant parenthood and the duty to be well. Sociological Inquiry, 81, 3, 285-309.

Øyen, L. and Aune, I. (2016) Viewing the unborn child - pregnant women's expectations, attitudes and experiences regarding foetal ultrasound examination, Sexual and Reproductive Health, 7, 8-13.

Parsons, E.P., Beale, V., Bennett, H., Jones, J. and Lycett, E.J. (2000) Reassurance through surveillance in the face of clinical uncertainty: the experience of women at risk of familial breast cancer, Health Expectations, 3, 4, 263-73.

Possamai-Inesedy, A. (2006) Confining risk: choice and responsibility in childbirth within a risk society, Health Sociology Review, 15, 4, 406-14.

Redshaw, M. and Heikkila, K. 2010. Delivered with Care: A National Survey of Women's Experience of Maternity Care. Oxford: National Perinatal Epidemiology Unit.

Reid, B., Sinclair, M., Barr, O., Dobbs, F. and Crealey, G. (2009) A meta-synthesis of pregnant women's decision-making processes with regard to antenatal screening for Down syndrome, Social Science $\mathcal{E}$ Medicine, 69, 11, 1561-73.

Roberts, J. (2012a) The Visualised Foetus: A Cultural and Political Analysis of Ultrasound Imagery. London: Routledge.

Roberts, J. (2012b) 'Wakey wakey baby': narrating four-dimensional (4D) bonding scans, Sociology of Health and Illness, 34, 2, 299-314.

Roberts, J., Griffiths, F.E. and Verran, A. (2015a) Seeing the baby, doing family: commercial ultrasound as family practice? Sociology, OnlineFirst.

Roberts, J., Griffiths, F.E., Verran, A. and Ayre, C. (2015b) Why do women seek ultrasound scans from commercial providers during pregnancy? Sociology of Health and Illness, 37, 4, 594-609.

Ross, E.J. (2015) 'I think it's self-preservation': risk perception and secrecy in early pregnancy, Health, Risk and Society, 17, 5-6, 329-48. 
Rothman, B.K. (1994) The Tentative Pregnancy: Amniocentesis and the Sexual Politics of Motherhood. London: Pandora.

Rothman, B.K. (2014). Pregnancy, birth and risk: an introduction, Health, Risk \& Society, 16, 1, 1-6.

Sandelowski, M. (1994) Separate, but less unequal: fetal ultrasonography and the transformation of expectant mother/fatherhood, Gender and Society, 8, 2, 230-45.

Siegel, M. (2014) The Rhetoric of Pregnancy. Chicago: University of Chicago Press.

Smith, R. P., S. Titmarsh and T. G. Overton (2004). Improving patients' knowledge of the fetal anomaly scan. Ultrasound in Obstetrics and Gynaecology, 24, 7, 740-44.

Taylor, J.S. (1998) Image of contradiction: obstetrical ultrasound in American culture. In Franklin, S. and Ragoné, H. (eds.) Reproducing Reproduction: Kinship, Power and Technological Innovation. Philadelphia: University of Pennsylvania Press, 15-45.

Taylor, J.S. (2008) The Public Life of the Fetal Sonogram: Technology, Consumption and the Politics of Reproduction. New Brunswick: Rutgers University Press.

Thomas, G.M. (2015) Picture perfect: '4D' ultrasound and the commoditisation of the private prenatal clinic. Journal of Consumer Culture, OnlineFirst.

Thomas, G.M. (2017) Down's Syndrome Screening and Reproductive Politics: Care, Choice, and Disability in the Prenatal Clinic. London: Routledge.

Thomas, G.M. and Lupton, D. (2016) Threats and thrills: pregnancy apps, risk, and consumption. Health, Risk and Society, 17, 7-8, 495-509.

van Ravesteijn, H., van Dijk, I., Darmon, D., van de Laar, F., Lucassen, P., Hartman, T.O., van Weel, C. and Speckens, A. (2012) The reassuring value of diagnostic tests: a systematic review, Patient Education and Counseling, 86, 1, 3-8.

West, J. and Oldfather, P. (1995) Pooled case comparison: an innovation for cross-case study. Qualitative Inquiry, 1, 4, 452-64. 
Whynes, D.K. (2002) Receipt of information and women's attitudes towards ultrasound scanning during pregnancy. Ultrasound in Obstetrics and Gynaecology, 19, 1, 7-12.

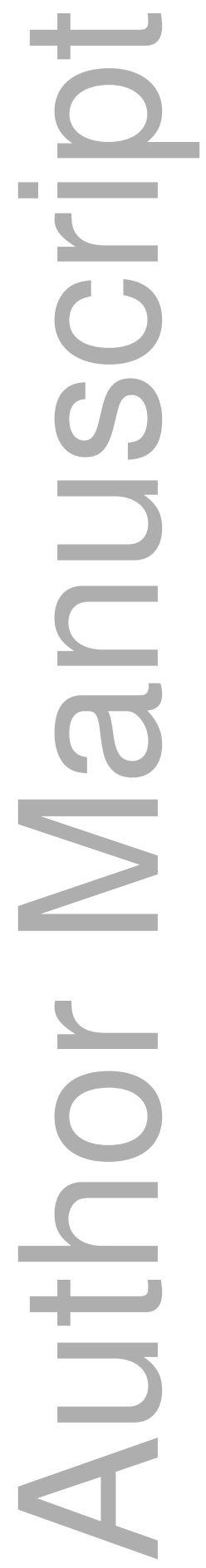




\section{University Library}

\section{- M M I N E R VA \\ A gateway to Melbourne's research publications}

Minerva Access is the Institutional Repository of The University of Melbourne

Author/s:

Thomas, GM;Roberts, J;Griffiths, FE

Title:

Ultrasound as a technology of reassurance? How pregnant women and health care professionals articulate ultrasound reassurance and its limitations

Date:

2017-07-01

\section{Citation:}

Thomas, G. M., Roberts, J. \& Griffiths, F. E. (2017). Ultrasound as a technology of reassurance? How pregnant women and health care professionals articulate ultrasound reassurance and its limitations. SOCIOLOGY OF HEALTH \& ILLNESS, 39 (6), pp.893-907. https://doi.org/10.1111/1467-9566.12554.

Persistent Link:

http://hdl.handle.net/11343/292686 